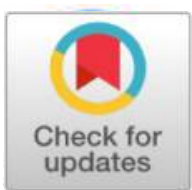

ORIGINAL CONTRIBUTION

\title{
Developing students' mathematical reasoning ability based on constructivist approach
}

\author{
Sunisa Pengmanee ${ }^{1, *}$ \\ ${ }^{1}$ International College, Suan Sunandha Rajabhat University, Bangkok, Thailand
}

\section{Keywords:}

Constructivist approach Mathematical reasoning open-ended problem Cooperative learning (think-pairshare)

Received: 14 May 2016

Accepted: 25 July 2016

Published: 12 August 2016

\begin{abstract}
The purpose of this action research was to develop students' mathematical reasoning ability based on a constructivist approach. The topic used in this study was 'functions.' The participants were 35 Grade 10 students from a mathematics class at a secondary school in Bangkok, Thailand, studying in 2015. The research instruments were nine lesson plans on functions, a formative test, and a summative test focusing on mathematical reasoning. In each lesson plan, the researcher integrated a constructivist approach and reasoning. In this action research, there were two cycles of the action plan. Each cycle was composed of planning, doing, checking, and reflecting. The criteria for evaluating students' reasoning ability were at least $70 \%$ of all students to pass both formative and summative tests. To pass each test, each student had to get at least $70 \%$ of total score. Teaching and learning lasted for 13 periods with 50 minutes in each period. The researcher applied open-ended problems and cooperative learning to construct students' knowledge and reasoning ability (think-pair-share). Data were collected and analyzed from formative and summative tests, students' homework, worksheets, and cooperative learning (think-pair-share). This study showed that mathematical reasoning ability increased to the expected level required by the researcher. So, using the constructivist approach through open-ended problems and cooperative learning (thinkpair-share) could increase students' reasoning ability.
\end{abstract}

(C) 2016 The Author(s). Published by TAF Publishing.

\section{INTRODUCTION}

Mathematics plays an important role in the development of the human thinking and reasoning. It enables one to make sound and precise analyses of various situations and leads to accurate predictions, appropriate planning, optimal problem-solving and decision-making in careers and daily life (Maldoon et al., 2013) Institute for the Promotion of Teaching Science and Technology (IPST) 2008.

Reasoning refers to the process of drawing conclusions or inferences from information (Mata et al., 2013). Reasoning always requires going beyond the information that is given (Bruner, 1957). It is necessary in learning process of the students. It also makes the process of thinking brighten up and allows

\footnotetext{
*Corresponding author: Sunisa Pengmanee

E-mail: sunisa_noomai@hotmail.com
}

The Author(s). Published by TAF Publishing. This is an Open Access article distributed under a Creative Commons AttributionNonCommercialNoDerivatives 4.0 International License 
students to learn and develop higher-order thinking skills (Blair, 2006; Cattell, 1987).

National Council of Teachers of Mathematics (NCTM) (2000) specifies the following goals to develop reasoning in student: first, developing students' reasoning bases on specific assumptions and rules and second, students should be encouraged to give reasons and to make conjectures, a great role in reasoning. NCTM envisions a progression of reasoning skills, beginning with trial-and-error strategies (which are then examined and analyzed) to conjecture strategies. With the development of mathematical reasoning, students will recognize that mathematics makes sense and can be understood.

They learn how to evaluate situations, select problem-solving strategies, draw logical conclusions, develop and describe solutions, and recognize how those solutions can be applied (Krulik and Jesse, 1993). Constructivism is a perspective on learning that is initiated from the learner's perspective rather than from that of the teacher; understanding is constructed by the learner rather than placed upon the learner.

Constructivist approach is based on the belief that learning occurs when learners are actively involved in a process of meaning and knowledge construction rather than when they passively receive information. Learners are the make+rs of meaning and knowledge.

In public school, many classrooms have students with a wide range of abilities but all are working towards the same goal. Students learn and understand mathematical concepts in many different ways (Simon et al., 2015; Waiyakoon, 2015). Teachers have the sometimes-difficult task of trying to identify which strategy works best for each individual student (Johnsen and Curtis, 2009).

The role of the teacher in constructivist classrooms is to organize information around big ideas that engage the students' interests, assist students in developing new insights, and connect them with their previous learning. The activities are student-centered, and students are encouraged to ask their own questions, carry out their own experiments, make their own analogies, and come to their own conclusions. The learner selects and transforms information, constructs hypotheses, and makes decisions relying on a cognitive structure to do so (Instructional Design, 2015).

From the class the researcher taught in the second semester of academic year 2015 , the main problem was about students' reasoning in mathematics. They did not realize the importance of reasoning and could not use it to support their answers. Therefore, the researcher planned to help the students by applying constructivist approach to be the framework and to use open ended problem and cooperative learning to help them develop their reasoning ability. The study was conducted in a classroom. Therefore, it was appropriate to apply action research in this study.

\section{LITERATURE REVIEW}

The purpose of this study was to determine what influence a constructivist teaching approach in a mathematics course had on developing students' reasoning ability. This review of literature includes: constructivist teaching approach, reasoning ability, open-ended problems and cooperative learning. 


\section{Constructivist Teaching Approach}

Confrey (1990) described constructivism as "a theory about the limits of human knowledge, a belief that all knowledge is necessarily a product of our own cognitive acts". Johnston (2005) described constructivism as an approach for teaching and learning based on the premise that cognition (learning) is the result of "mental construction." In other words, students learn by fitting new information together with what they have already known. Ross (2006) stated that constructivist teaching approaches play an important role in developing students' conceptual understanding and ability to communicate learned ideas. These approaches include teacher encouragement of students' independent thinking, creation of problem-centered lessons, and facilitation of shared meanings. The theory of constructivism is the basis for such teaching approaches. Driver and Valerie (1986) as cited in Matthews outlined the following constructivist teaching steps:

1. Orientation-The motivating step that promotes students' awareness of aim and finds out why this topic is important and worth learning.

2.Elicitation-Students articulate their current understanding of the topic through various activities such as group discussion, self-assessment activity, etc. 3.Turning restructuring of ideas-The "heart of the constructivist learning sequence" which takes place through:

a. Clarification and exchange of ideas-Where students contrast their understanding with those of others, including classmates, and instructor. These often conflict and come about through discussions or demonstrations.

b. Construction of new ideas-In light of the cognitive dissonance experienced, students see that there are numerous ways to interpret "phenomena or evidences".

c. Evaluation of new ideas-Students may experience a sense of dissatisfaction with their currently held views. They test new ideas, and evaluate through experimentation, or reflection on implications of new understanding or new information.

4. Application of Ideas-Newly developed ideas are used in a variety of situations.

5. Review-The meta-cognitive stage, where students reflect on how their understanding has evolved in light of the previous steps.

Hanley (1994) summarized the role of teachers in a class based on constructivism that teachers should be one of many resources that the student may learn from - not the primary source of information.

\section{Reasoning Ability}

Reasoning refers to the process of drawing conclusions or inferences from information. Reasoning always requires going beyond the information that is given (Bruner, 1957). It is necessary in learning process of the students. It also makes the process of thinking brighten up and allows students to learn and develop higher-order thinking skills (Blair, 2006; Cattell, 1987).

The reasoning ability is the ability to think reasonably and solve problems in new situations that is independent of acquired prior knowledge (Cattell, 1987). The reasoning is an important element of cognitive development (Goswami, 1992), while the reasoning ability will be to act as a supplement to a child's ability on the other side (Blair, 2006; Cattell, 1987). 
Mathematical reasoning refers to the ability to analyze mathematical situations and construct logical arguments. It is the critical skill that enables a student to make use of all other mathematical skills. With the development of mathematical reasoning, students recognize that mathematics makes sense and can be understood. They learn how to evaluate situations, select problemsolving strategies, draw logical conclusions, develop and describe solutions, and recognize how those solutions can be applied. Mathematical reasoning is able to reflect on solutions to problems and determine whether or not they make sense. Students appreciate the pervasive use and power of reasoning as a part of mathematics (New Jersey Mathematics Curriculum Framework, 1996).

National Council of Teachers of Mathematics (NCTM) (2000) specifies that developing students' reasoning bases on specific assumptions and rules, and students should be encouraged to give reasons and to make conjectures. NCTM assigns conjecture a great role in reasoning. It envisions a progression of reasoning skills, beginning with trial-and-error strategies (which are then examined and analyzed) to conjecture strategies.

\section{Cooperative Learning}

Co-operative learning is both an instructional technique and teaching philosophy that encourages students to work together to maximize learning. In its simplest form, co-operative learning is a type of group work in which two or more students interact with the common goal of mastering specific academic material.

Think-Pair-Share is a type of cooperative learning strategy that can promote and support higher-level thinking. It is a strategy easy to implement in any classroom at any grade level or subject. This strategy does not require any other change in pedagogy or materials. The teacher asks students to think about a specific topic, then pair with another student to discuss their thinking. For pairshare, teachers merely ask a question or assign a problem and allow students to think and work with a partner for one to three minutes before requesting an answer to the question or problem, after that, they share their ideas with the group (Workshop, 2005).

In think-pair-share, students are given a brief period of time to think independently before working with a partner. While effective in results, this strategy is a significant first step in engaging all students in classroom instructional activities. Simon (2016) stated that the Think-Pair-Share strategy is designed to encourage a high degree of student response, rather than using a basic recitation method. This strategy provides an opportunity for all students to share their thinking with at least one other student which increases their sense of involvement in classroom learning.

\section{Open-Ended Problems}

An open-ended problem is a problem that has several or many correct answers, and several ways to the correct answers. The Open-Ended Problem is based on the research conducted by Shimada (1977) which is called "The Open-Ended Approach". The Open-Ended Approach provides students with "experience in finding something new in the process" Akihiko as cited in Becker and Shimada, (1997). 
The Open-Ended Approach started in 1970s. Since then, Japanese teachers have developed many open-ended problems and lesson plans using open-ended problems. These problems are being used in mathematics lessons ranging from elementary through high school grades, and the lessons are called the OpenEnded Problem Solving. Open-ended problems are also used as assessment tasks because "In responding to such (open-ended) items, students are often asked not only to show their work, but also to explain how they got their answers or why they chose the method they did" Akihiko, as cited in Schoenfeld (1992)

Open-ended question is question that has more than one right answer, or one that can be answered in many ways. This way of asking questions stimulates more language use, acknowledges that there can be many solutions to one problem, affirms students' ideas, and encourages creative thinking. Students must have a high level of verbal skills to respond to open-ended questions. Because open-ended questions have a wide-range of possible answers, students are able to respond only if they have a fairly high level of verbal skills, vocabulary, and self-confidence.

The success of open-ended questions depends on the teacher's ability to understand the students' interest or focus. The teacher may be used to asking questions aimed at assessing how much a student knows (about color, number, shape or alphabet) and may find it difficult at first to ask engaging questions with no right answer. Close-ended questions usually end conversations. Openended questions that are too general or unfocused may be difficult for the students to respond to and may also end the conversation. There are five advantages that can be summarized, based on what Sawada (1997) mentioned in 1977.

1) Students participate more actively in lessons and express their ideas more frequently. The Open-Ended Problem Solving provides free, responsive, and supportive learning environment because there are many different correct solutions, so that each student has opportunities to get own unique answers. Therefore, students are curious about other solutions, and they can compare and discuss about their solutions with each other. As students are very active, it brings a lot of interesting conversation to the classroom.

2) Students have more opportunities to make comprehensive use of their mathematical knowledge and skills. Since there are many different solutions, students can choose their favorite ways towards the answers and create their unique solutions. Activities can be the opportunities to make comprehensive use of their mathematical knowledge and skills.

3) Every student can respond to the problem in some significant ways of his/ her own.

4) The lesson can provide students with a reasoning experience. Through the comparing and discussing in the classroom, students are intrinsically motivated to give reasons of their solutions to other students. It is a great opportunity for students to develop their mathematical thinking.

5) There are rich experiences for students to have pleasure of discovery and to receive the approval from fellow students. Since every student has each solution based on each unique thinking, every student is interested in fellow students' solutions. 


\section{METHODOLOGY}

\section{Participants}

The participants in this study were 35 students in Grade 10 of a secondary school in Bangkok, Thailand at the second semester of the academic year 2015.

\section{Research Instruments}

Research instruments were nine lesson plans on functions, formative test and summative test. There were nine lesson plans on functions integrated in constructivist approach to improve mathematical reasoning. The lesson plan scope and sequence were shown in Table 1.

TABLE 1. Lesson plans on functions

\begin{tabular}{clc}
\hline $\begin{array}{c}\text { Lesson plans } \\
\text { No. }\end{array}$ & Contents & $\begin{array}{c}\text { Period } \\
\text { (50 minutes) }\end{array}$ \\
\hline 1 & Definition of a function & 1 \\
\hline 2 & The values of functions & 1 \\
\hline 3 & Kinds of functions & 1 \\
\hline 4 & Increasing and decreasing functions & 1 \\
\hline & Reflection 1 & $\mathbf{1}$ \\
\hline & Formative test (6 written items) & 1 \\
\hline 5 & Constant functions and linear functions & 2 \\
\hline 7 & Quadratic functions & 2 \\
\hline & Using graphing and quadratic functions to solve problems & 1 \\
\hline 9 & Reflection 2 & 1 \\
\hline & Exponential functions and step functions & $\mathbf{1}$ \\
\hline
\end{tabular}

Table 1 showed contents and time to spend in each lesson plan with five steps in teaching. The steps included: 1) orientation, 2) elicitation of the prior knowledge, 3) turning restructuring of ideas (clarification and exchange of ideas, construction of new ideas and evaluation of the new ideas), 4) application of ideas, and 5) review.

After that, the researcher reflected on students' behaviors and results for improvement in the next period. In implementing each lesson plan, the researcher emphasized reasoning through constructivist approach by openended questions and cooperative learning (think-pair-share). The researcher investigated students' reasoning ability from the results of formative test and summative test.

Each formative test and summative test consisted of six written items. In measuring students' mathematics reasoning ability, the researcher adapted reasoning scoring criterion from that of Exemplars 2016 as shown in Table 2. Formative and summative tests were written tests. Each item was evaluated by 
scoring criterion from that of Exemplars 2016. The total score of each item was

4. Table 2 showed scoring criterion of each test item.

Students' handouts, homework, cooperative learning (think-pair-share) and worksheets were distributed at the end of each period. They were also used to consider students' mathematics reasoning ability.

\section{Data Collection}

The data collection of this study was performed during 13 periods of instruction, as described in the previous section. During the study period, the participants received learning instruction based on a constructivist approach. Then, all participants were asked to take the formative test after finishing the fourth period. After the formative test, the teacher continued the instruction as specified in the lesson plans for resolving the problems found in the fourth period. The participants took summative test at the final period. Then the researcher analyzed and interpreted the data.

TABLE 2. Description of scoring mathematics reasoning ability

\begin{tabular}{ccl}
\hline \hline Scores & Levels & \multicolumn{1}{c}{ Reasoning ability } \\
\hline 4 & Superior & $\begin{array}{l}\text { Deductive arguments are used to justify decisions and may result in formal proofs. } \\
\text { Evidence is used to justify and support decisions made and conclusions reached. }\end{array}$ \\
\hline 3 & Good & $\begin{array}{l}\text { Arguments are constructed with adequate mathematical basis. } \\
\text { A systematic approach and/or justification of correct reasoning is presented. }\end{array}$ \\
\hline 2 & Average & $\begin{array}{l}\text { Arguments are made with some mathematical basis. } \\
\text { Some correct reasoning or justification for reasoning is presented. }\end{array}$ \\
\hline 1 & Below Average & $\begin{array}{l}\text { Arguments are made with no mathematical basis. } \\
\text { No correct reasoning nor justification for reasoning is presented. }\end{array}$ \\
\hline 0 & Non-Existent & No idea for the reasoning or impasse. \\
\hline \hline
\end{tabular}

\section{Data Analysis}

For analyzing tests, the researcher used Index of Item Objective Congruency (IOC) to consider congruence between test items and their objectives. IOC was calculated by the formula (Boonchom, 2002). For analyzing of research objective, the researcher used scoring mathematics reasoning ability from that of Exemplars 2016.

\section{RESULTS}

This study aimed at developing students' mathematical reasoning ability based on constructivist approach. The criterion to evaluate students' reasoning ability was that at least $70 \%$ of all students should pass both formative test and summative test. To pass each test, each student had to get at least $70 \%$ of total score.

The analysis was composed of four sections as follows: 1) results of students' mathematics formative test, 2) results from analysis of students' mathematics summative test, 3) results from analysis of students' both mathematics tests and 4) students' progress considered from students' homework, worksheet and 
cooperative learning (think-pair-share). Each section related to the objective in this study and was described in details as follows:

\section{Results of Formative Test}

Results of students' mathematics formative test were shown in Table 3.

TABLE 3. Results of formative test

\begin{tabular}{|c|c|c|c|c|}
\hline \multirow{2}{*}{ Item } & \multirow{2}{*}{$\mathrm{n}$} & \multicolumn{2}{|c|}{ Overall score ( 24 points) } & \multirow{2}{*}{$\begin{array}{c}\text { Number of students passing } \\
\text { above } 70 \%\end{array}$} \\
\hline & & $\overline{\mathrm{X}}$ & S.D & \\
\hline Formative Test & 35 & 17.71 & 3.12 & $25(71.43 \%)$ \\
\hline
\end{tabular}

Table 3 revealed that the constructivist lesson plans were effective in developing students' reasoning ability in mathematics since more than $70 \%$ of the participants passed formative test.

\section{Results of Summative Test}

Results from analysis of students' mathematics summative test were presented in Table 4.

TABLE 4. Results of summative test

\begin{tabular}{|c|c|c|c|c|}
\hline \multirow{2}{*}{ Item } & \multirow{2}{*}{$\mathrm{n}$} & \multicolumn{2}{|c|}{ Overall score (24 points) } & \multirow{2}{*}{$\begin{array}{l}\text { Number of students passing above } \\
\mathbf{7 0 \%} \\
\end{array}$} \\
\hline & & $\overline{\mathrm{X}}$ & S.D & \\
\hline $\begin{array}{c}\text { Summative } \\
\text { Test }\end{array}$ & 35 & 19.77 & 2.77 & 27 (77.14 \%) \\
\hline
\end{tabular}

Table 4 demonstrated that the constructivist lesson plans were effective in developing students' reasoning ability in mathematics since more than $70 \%$ of the participants passed summative test.

Results of Formative Test and Summative Test

Summary from analysis of students' both mathematics tests were shown in Table 5.

TABLE 5. Summary of both tests

\begin{tabular}{|c|c|c|c|}
\hline \multirow{2}{*}{ Item } & \multicolumn{2}{|c|}{ Overall score ( 24 points) } & \multirow{2}{*}{$\begin{array}{c}\text { Number of students passing } \\
\text { above } 70 \%\end{array}$} \\
\hline & $\bar{X}$ & S.D & \\
\hline Formative Test & 17.71 & 3.12 & $25(71.43 \%)$ \\
\hline Summative Test & 19.77 & 2.77 & $27(77.14 \%)$ \\
\hline
\end{tabular}

Table 5 showed that the constructivist lesson plans were effective in developing students' reasoning ability in mathematics since more than $70 \%$ of the participants have the average scores attained above the expected level at $70 \%$ of the total scores in both tests. Results of Students' homework, Work 
Sheets and Cooperative learning (think-pair-share). Students' homework, worksheets, and cooperative learning (think-pair-share) were used to consider the development of the students' mathematics reasoning ability.

For homework and worksheets, the results showed that during the first few period of class, students adopted a definition used as a reason to answer only which could not lead to any other mathematical knowledge or their own reasoning to support answers. After that, students developed more clear reasoning. They can summarize their own answer using definition and can adopt other mathematical knowledge or their own reasoning to support answers. For example, when the researcher gave homework, "Is the relation $\mathrm{x}=$ $|y|$ a function?" They can write the reason that this relation is not a function because the ordered pairs $(1,1)$ and $(1,-1)$ are members of this relation which do not satisfy the definition of functions.

In cooperative learning (think-pair-share), it was found that in the first two periods, students summarized their own answers and did not discuss with their friends. So, there was no final answer for class presentation. They did not review previous knowledge relevant to the presentation. After that, students started presenting and discussing with their friends before settling on a final answer. They made the rest of students understand more by reviewing previous knowledge and using mathematical knowledge to solve problems and used it to explain the answers very well.

\section{DISCUSSION AND CONCLUSION}

This action research applying constructivist approach was to improve students' mathematical reasoning ability. The topic used in this study was functions in Grade 10. The researcher developed the research instruments composed of: 1) nine lesson plans that integrated five steps in teaching which are orientation, elicitation, restructuring of ideas (clarification and exchange of ideas, construction of new ideas, and evaluation of the new ideas), application of ideas, and review, and 2) formative test and summative test. The lesson plans were applied to 35 Grade 10 students with two cycles of action research; each cycle was composed of plan, do, check, and reflect. The formative test and summative test were of determined content validity by using index of Item Objective Congruence (IOC) judged by three experts.

In the first six periods, students' mathematical reasoning ability was shown by the score of formative test. The number of students having the average scores of this test passing above $70 \%$ of total score, represented $71.43 \%$ ( 25 students) and after 12 periods, the number of students having the average scores of summative test passing above $70 \%$ of total score represented $77.84 \%$ (27 students), respectively.

In addition, the researcher considered students' homework, worksheets and cooperative learning (think-pair-share). Students showed gradual development of their reasoning ability. They could summarize their own answers using definitions and other mathematical knowledge to support answers. Students settled on final answers after considering and discussing with their friends. They reviewed previous knowledge to explain the reasons before presenting to their friends and students settled on a final answer after discussing with their partners. The increasing of students' reasoning abilities results from constructivist approach. Also, students applied reasoning to construct 
knowledge themselves. Moreover, the cooperative learning (think-pair-share) increased their discussion, thinking, and reasoning ability.

\section{CONCLUSION}

The findings of this study showed that using the constructivist approach in the mathematics classroom could improve students' mathematical reasoning abilities. Furthermore, implementation of the constructivist approach should be intensively studied about knowledge and skills of students. In this case, training and continuous development is needed for students to develop mathematics reasoning ability. Students can learn from each other and can construct knowledge and reasoning ability. Their experiences can be shared with each other to understand and increase reasoning skill. According to Ross (2006), she specified that constructivist teaching approaches play an important role in developing students' conceptual understanding and ability to communicate learned ideas. Students were more engaged with constructivist approaches. Piaget (1954) also addressed that when students are engaged, they could easily be working with hands-on materials, while portraying independent thinking in collaboration with others on investigative, cumulative mathematics problems and they could actively be constructing their own meaning.

\section{LIMITATIONS AND RECOMMEDNATIONS}

This study has some limitations. This study took grad 10 students as research subjects and developed a lesson plan for a particular topic. Although, the plan proposed in this study rendered fruitful results, yet, author/s cannot vouch for such methods. Therefore, to lend confidence in the findings of this study, more similar studies must be carried out in future.

\section{ACKNOWLEDGMENT}

Thanks to the Institute for the Promotion of Teaching Science and Technology (IPST) and the government of Thailand, for providing me with the Project for Promotion of Science and Mathematics Talented Teacher (PSMT) scholarship and to International College, Suan Sunandha Rajabhat University (SSRUIC), for providing me with the program of Mathematics Education. I would like to express my appreciation to students who participated in the research practicum school, Satriwitthaya School, Bangkok, Thailand. I also offer my sincere appreciation to Asst. Prof. Dr. Supotch Chaiyasang, Assoc. Prof. Chaweewan Kaewsaiha, and Dr. Kanokrat Kunasaraphan from Mathematics Education Program for their invaluable comments to review this research report.

\section{REFERENCES}

Becker, Jerry P., and Shimada Shigeru. (Eds). 1997. The open-ended approach: A new proposal for teaching mathematics. Reston, VA: National Council of Teachers of Mathematics.

Blair, Clancy. 2006. How similar are fluid cognition and general intelligence? A developmental neuroscience perspective on fluid cognition as an aspect of human cognitive ability. Behavioral and Brain Sciences 29, no. 2: 109-125. DOI: $10.1017 / \mathrm{S} 0140525 \mathrm{X} 06419038$

Bruner, Jerome S. (Ed.). (1957). Going beyond the information given. In Contemporary approaches to cognition: $A$ symposium held at the University of Colorado, ed, 41-69. Cambridge, MA: Harvard University Press.

Cattell, Raymond B. (1987). Intelligence: Its structure, growth and action. North-Holland, NL: Elsevier. 
Confrey J. 1990. What constructivism implies for teaching: Constructivist views on the teaching and learning of mathematics. Reston, VA: National Council of Teachers of Mathematics.

Driver, Rosalind, and Valerie Oldham. 1986. A constructivist approach to curriculum development. Studies in Science

Education 13, no. 1: 105-122. D0I: 10.1080/03057268608559933

Goswami, Usha. 1992. Analogical reasoning in children. Hillsdale, NJ: Lawrence Erlbaum.

Hanley, Susan. 1994. On constructivism. maryland collaborative for teacher preparation, college park. URL: http://goo.gl/RflInQ (accessed July 15, 2016).

Instructional Design. 2015. Constructivist Theory (Jerome Bruner). URL: http://goo.gl/1jHwRd (accessed 26 July, 2016).

Johnsen, Scott, and Curtis Ne. 2009. Improving achievement and attitude through cooperative learning in math. Action Research Projects, Department of Mathematics, University of Nebraska-Lincoln, NE. URL: http://goo.gl/c5N6TT (accessed 26 July, 2016).

Johnston, Howard. 2005. The principals' partnership: Constructivist teaching and learning, pathways to school improvement. University of South Florida, Florida, FL.

Krulik, Stephen, and Jesse A. Rudnick. 1993. Problem solving: A handbook for teachers. 2nd ed. Boston, MA: Allyn and Bacon.

Mata, André, Klaus Fiedler, Mário B. Ferreira, and Tiago Almeida. 2013. Reasoning about others' reasoning. Journal of Experimental Social Psychology 49, no. 3: 486-491.

Muldoon, Kevin, John Towse, Victoria Simms, Oliver Perra, and Victoria Menzies. 2013. A longitudinal analysis of estimation, counting skills, and mathematical ability across the first school year. Developmental psychology 49, no. 2 (2013): 250.

National Council of Teachers of Mathematics (NCTM). 2000. Principles and standards for school mathematics. Reston, VA: National Council of Teacher of Mathematics.

New Jersey Mathematics Curriculum Framework . 2006. The first four standards, standard 4-reasoning; K-12 overview. URL: http://goo.gl/NBxCTv (accessed July 16, 2016).

Piaget, Jean. 1954. The construction of reality in the child. New York, NY: Basic Books. DOI: 10.1037/11168-000

Ross, Amanda A. 2006. The effects of constructivist teaching approaches on middle school students' algebraic understanding. Ph.D. dissertation, Texas A\&M University, Texas, TX.

Sawada, T. 1997. Developing lesson plans. In The open-ended approach: A new proposal for teaching mathematics, eds. Becker, Jerry P., and Shimada, Shigeru. Reston, VA: National Council of Teachers of Mathematics.

Schoenfeld, Alan H. 1992. Learning to think mathematically: Problem solving, metacognition, and sense making in mathematics. In Handbook of research on mathematics teaching and learning, ed. Douglas A. Grouws. New York, NY: Macmillan.

Shimada, Shigeru. 1977. Open-end approach in arithmetic and mathematics: A new-proposal toward teaching improvement. Tokyo, JP: Mizuumishobo.

Simon, C. Allen. 2016. Research basis. URL: http://goo.gl/5zCNQC (accessed July 15, 2016).

Simon, M. A., Melike Kara, Nicora Placa, and Hakan Sandir. 2013. Categorizing and promoting reversibility of mathematical concepts. Educational Studies in Mathematics 93, no. 2: 137-153.

Waiyakoon, Suwit, Jintavee Khlaisang, and Prakob Koraneekij. 2015. Development of an instructional learning object design model for tablets using game-based learning with scaffolding to enhance mathematical concepts for mathematic learning disability students. Procedia-Social and Behavioral Sciences 174: 1489-1496.

Workshop. (2005). Cooperative learning: Think-pair-share strategy. URL: http://goo.gl/uuDjvV (accessed on July 16, 2015). 